\title{
Serum Heparan Sulfate Levels are Elevated in Endotoxemia
}

\author{
K. F. Hofmann-Kiefer ${ }^{1 *}$, G. I. Kemming ${ }^{2,5 *}$, D. Chappell ${ }^{1}$, M. Flondor ${ }^{1,5}$, H. Kisch-Wedel ${ }^{1,5}$, \\ A. Hanser ${ }^{3,5}$, S. Pallivathukal 4, 5, P. Conzen ${ }^{1}$, M. Rehm ${ }^{1}$ \\ ${ }^{1}$ Clinic of Anesthesiology/Critical Care Medicine and Pain Therapy (M.A.B., P.C), Ludwig-Maximilians-University, City of Munich, \\ ${ }^{2}$ Department of Anesthesiology and Intensive Care Medicine, Kreiskliniken Günzburg-Krumbach, City of Günzburg, \\ ${ }^{3}$ Clinic of Pediatrics, Common Hospital, City of Augsburg, \\ ${ }^{4}$ Department of Neonatology. Clinic of Gynaecology and Obstetrics, Ludwig-Maximilians-University, City of Munich, \\ ${ }^{5}$ Institute for Surgical Research, Ludwig-Maximilians-University, City of Munich, Germany
}

\begin{abstract}
Background: Increased vascular permeability is a characteristic feature of sepsis which, in the past, has been ascribed exclusively to a malfunction of endothelial cells. However, recently it has become evident that the endothelial glycocalyx is of considerable importance concerning various aspects of vascular physiology, e.g. the vascular barrier and inflammation. Heparan sulfate, one of its essential components is characteristically traceable in blood, in case the endothelial glycocalyx is damaged or destroyed.

Methods: In 15 pigs we investigated whether the administration of endotoxin from gram-negative bacteria (Escherichia coli) results in increased serum levels of heparan sulfate, signalizing a shedding of the glycocalyx. In addition, markers of inflammation (white blood cell count, platelet count, tumour necrosis factor- $\alpha$ and interleukin-6) were evaluated over an observation period of 6 hours.

Results: Serum heparan sulfate concentrations significantly increased over time in the endotoxin group and were significantly elevated in comparison to the control group 6 hours after administration of endotoxin $(p<0.001)$. In the endotoxin group all markers of inflammation significantly changed during the time course.

Conclusions: The administration of bacterial endotoxin induced a significant rise in degradation products of the endothelial glycocalyx.
\end{abstract}

Key words: Glycocalyx; Sepsis; Heparan Sulfate; Leukocyte Adhesion, Endotoxin

\section{INTRODUCTION}

A healthy vascular endothelium is coated by an endothelial glycocalyx (EGX), which, in some regions of the vascular bed, has proved to be even thicker than the endothelial cells [1]. This EGX consists of extracellular domains of molecules such as transmembrane syndecans and membrane-bound glypicans that both * K. Hofmann-Kiefer and G. Kemming contributed to this
work in equal parts. contain covalently bound, highly negatively charged glycosaminoglycans (GAGs), mainly heparan sulphate $[2,3]$. The physiological importance of the endothelial glycocalyx has not been realized for many years, but recent evidence has shown the EGX to play a key role concerning various aspects of vascular physiology.

The EGX has considerable influence on transvascular fluid exchange $[1,4]$. Thus, it has been identified as a competent barrier against extravasation of fluids and colloids [1,4-6]. The EGX is involved in inflammatory processes and immune reactions [7, 8] and mediates the release of vasoregulatory agents such as nitric oxid [9-11]. Another important biological property of the EGX may be the ability to keep circulating blood cells in distance to the endothelial cells in order to prevent cell adhesion $[12,13]$. It is well recognized that exposure to oxidized lipoprotein $[14,15]$ or tumor necrosis factor- $\alpha[16,17]$ can reduce the thickness of the EGX. Ischemia/reperfusion [7, 18-20] as well as excretion of atrial natriuretic peptide $[6,21]$ induces shedding of the EGX. This degradation of the EGX is associated with an increase of the major EGX components heparan sulfate (HS) and syndecan-1 in the circulating blood.

These new findings [22-24] suggest an alteration of the EGX by endotoxemia. Hence, the aim of the current experimental study was to explore, whether the application of bacterial endotoxin in an animal model, causes destruction of the EGX and, therefore, the vascular barrier. After endotoxin administration we measured serum concentrations of HS being one of the main components of the EGX as target parameter of the investigation.

\section{Material And Methods}

The investigation conforms to the Guide for the Care and Use of Laboratory Animals published by the US National Institutes of Health. The study was approved by the officially installed, independent Ethics Committee of the State of Bavaria and by the Bavarian Government (both Munich, Germany). It was conducted in 15 pigs (German landrace; body weight $29 \pm 4.2$ $\mathrm{kg}$ ), which were treated and housed in accordance with the principles of laboratory animal care. 


\section{Monitoring:}

In order to maintain stable hemodynamic conditions during endotoxemia, the animals had to be monitored: For measurement of arterial blood pressure and left ventricular enddiastolic pressure a femoral arterial introducer sheath (8.5 French; Arrow, Reading, PA) as well as a thermodilution pulmonary artery catheter (7.5 French, REF-1; Baxter, Irvine, CA) were inserted. A central venous catheter (14 gauge; Arrow; vena femoralis) allowed for continuous drug administration. In order to guaranty normal respiratory conditions the animals were anesthetized and artificially ventilated during the procedure (airway pressures of $28 \pm 3 / 11$ $\pm 2 / 5 \pm 1$ at peak / mean / end-expiration; controlled minute ventilation at a fractional inspiratory oxygen concentration of 1.0, Servo 900 B; Siemens, Solna, Sweden).

\section{Anesthesia:}

After the pigs were fasted for one night with free access to water, intramuscular premedication was performed with midazolam $(1 \mathrm{mg} / \mathrm{kg})$ and ketamine $(10 \mathrm{mg} / \mathrm{kg})$. Anesthesia was induced by intravenous injection of fentanyl $(20 \mu \mathrm{g} / \mathrm{kg})$, propofol $(3 \mathrm{mg} / \mathrm{kg})$, and muscular paralysis was induced by a single dose of atracurium besilate $(0.7 \mathrm{mg} / \mathrm{kg})$. Total intravenous anesthesia was maintained by continuous intravenous infusion of propofol $(10 \mathrm{mg} / \mathrm{kg} \bullet \mathrm{h}$, midazolam $(1.5 \mathrm{mg} / \mathrm{kg} \bullet \mathrm{h})$, and fentanyl $(45 \mu \mathrm{g} / \mathrm{kg} \bullet \mathrm{h})$. Based on repeated blood gas analyses, minute ventilation was adjusted to preserve normocapnia. Normothermia was ensured by means of a warming pad and a warming lamp.

\section{Fluid Therapy:}

We used Ringer's solution for fluid replacement (15 $\mathrm{ml} / \mathrm{kg} \bullet \mathrm{h}$ ). Additional fluid therapy consisting to equal parts of Ringer's solution and pentastarch $(6 \%$ hydroxyethyl starch 200,000/0.5; Fresenius-Kabi, Bad Homburg, Germany) was given at constant rates up to $60 \mathrm{ml} / \mathrm{kg} \bullet \mathrm{h}$, as necessary to maintain a constant left ventricular preload (end-diastolic pressure $8 \mathrm{mmHg}$ ). However, the administration of fluid boluses was avoided. Intravenous norepinephrine was given continuously as necessary to maintain mean arterial pressure at $70 \mathrm{mmHg}$.

After randomization using closed envelopes we administered endotoxin of Escherichia coli 111:B4; 1 $\mathrm{mg} / \mathrm{kg} \bullet \mathrm{h}$ for $1 \mathrm{~h}$ and afterwards $10 \mathrm{mg} / \mathrm{kg} \bullet \mathrm{h}$ for $5 \mathrm{~h}$ via the central intravenous line in 8 animals (endotoxin group (EG)). 7 animals were observed over time without further intervention (control group (CG)). In addition, hemodynamic parameters (mean arterial blood pressure (MAP), left ventricular enddiastolic pressure (LVEDP), as well as ventilatory parameters $\left(\mathrm{PaO}_{2}\right.$, $\mathrm{PaCO}_{2}$, minute-ventilation) were recorded continuously.

\section{Measurements:}

We assessed serum heparan sulfate, white blood cell count (WBC), platelet count (PLT) and serum hemoglobin concentrations at baseline (T0) i.e. immediately before endotoxin administration, as well as $3 \mathrm{~h}$ (T1) and $6 \mathrm{~h}$ (T2) after the start of endotoxin administration. Tumor necrosis factor- $\alpha(\mathrm{TNF} \alpha)$ and interleukin
6 (IL-6) were measured at baseline and $6 \mathrm{~h}$ after the start of the endotoxin administration. HS concentrations were measured using ELISA-kits (Seikagaku Inc., Japan) as described in detail elsewhere $[4,6]$.

\section{Statistical Analysis:}

Physiological data were tested for normal distribution with a Kolmogorov-Smirnov-Test. Because most of the data were distributed normally, they are presented as mean \pm standard deviation. We used a repeated measurement analysis of variances (RM-ANOVA) followed by a Student-Newman-Keuls Test to describe changes of measurement parameters within a group during the course of time ( 3 points of measurement). Equality of co-variances was tested with help of the Box-M Statistic followed by Mauchly's Test to check for sphericity and used the Greenhouse-Geisser-Epsilon correction if necessary. In the case of not normally distributed data we practised a repeated measurement ANOVA on ranks (Friedman Test)

In order to compare differences between the groups a RM-ANOVA was followed by a StudentNewmann-Keuls Test (see above). If data were not normally distributed a one way ANOVA on ranks (Kruskal-Wallace Test) was followed by Dunn's Test. For all determinations a type I error protection of $\mathrm{p}<$ 0.05 was considered significant. Statistical analysis was performed using Sigma Stat Software Version 3.1 (RockWare Inc. Golden, USA), SPSS Software Version 15.0.1 (SPSS Inc. Chicago, USA) and Microsoft Excel Version 2003 (Microsoft Deutschland GmbH, Unterschleißheim, Germany).

\section{RESULTS}

At baseline, values displayed no differences between the groups. In 8 animals, endotoxin was administered and a complete data set was obtained.

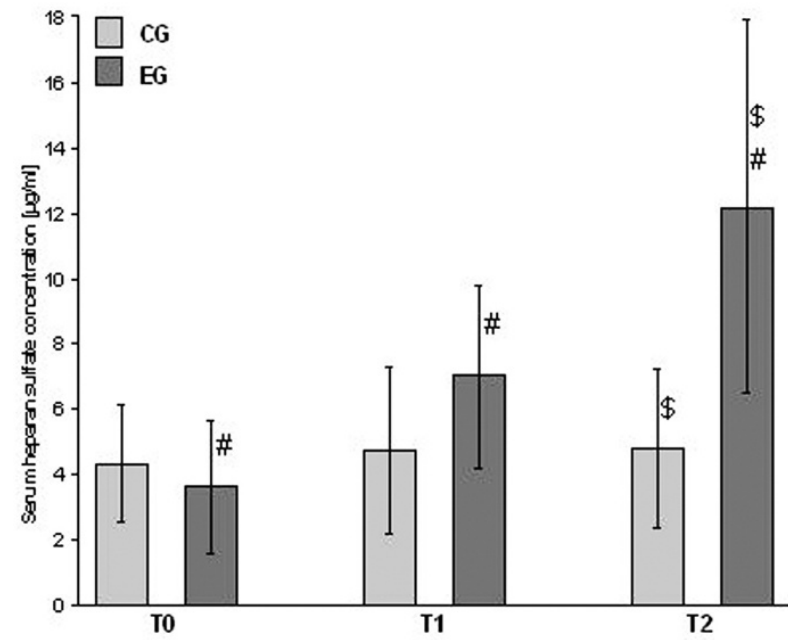

Fig. 1. Time course of serum heparan sulfate concentrations after administration of endotoxin (T0). Endotoxin group: \# : $\mathrm{p}<0.001$ for T2 versus T0; $\mathrm{p}<0.001$ for T2 versus T1. Comparison between groups: $\$: \mathrm{p}<0.001$ for T2. T0: Baseline, immediately before endotoxin administration; $\mathrm{T} 1: 3 \mathrm{~h}$ after endotoxin administration; T2: $6 \mathrm{~h}$ after endotoxin administration. Values are mean $\pm \mathrm{SD}$ 
Table 1. Laboratory Parameters.

\begin{tabular}{|c|c|c|c|}
\hline & Baseline & $\begin{array}{l}\text { Point of Measurem } \\
3 \text { h after Endotoxin }\end{array}$ & $6 \mathrm{~h}$ after Endotoxin \\
\hline \multicolumn{4}{|c|}{ WBC $\left[1000 / \mathrm{mm}^{3}\right]$} \\
\hline Endotoxin* & $8.4 \pm 3.7$ & $5.3 \pm 1.7 \#$ & $1.5 \pm 0.3 \#$ \\
\hline Control & $7.6 \pm 1.9$ & $8.2 \pm 3.1$ & $9.0 \pm 3.2$ \\
\hline \multicolumn{4}{|c|}{ PLT $\left[1000 / \mathrm{mm}^{3}\right]$} \\
\hline Endotoxin* & $270.6 \pm 35.9$ & $191.6 \pm 80.9$ & $93.0 \pm 35.5 \#$ \\
\hline Control & $307.0 \pm 132.5$ & $254.7 \pm 135.5$ & $206.7 \pm 70.5$ \\
\hline \multicolumn{4}{|l|}{ IL6 [pg/ml] } \\
\hline Endotoxin* & $2.3 \pm 4.7$ & n.d. & $3810.6 \pm 90.6 \#$ \\
\hline Control* & $2.0 \pm 1.2$ & n.d. & $75.2 \pm 67.1$ \\
\hline \multicolumn{4}{|c|}{ TNF- $\alpha$ [pg/ml] } \\
\hline Endotoxin* & $196.3 \pm 116.7$ & n.d. & $1921.2 \pm 512.4 \#$ \\
\hline Control & $106.9 \pm 36.6$ & n.d. & $136.9 \pm 293.3$ \\
\hline \multicolumn{4}{|l|}{$\mathrm{Hb}[\mathrm{g} / \mathrm{dl}]$} \\
\hline Endotoxin & $8.4 \pm 0.8$ & $9.0 \pm 0.7$ & $8.5 \pm 1.5$ \\
\hline Control & $9.2 \pm 0.5$ & $9.0 \pm 0.5$ & $9.0 \pm 0.5$ \\
\hline
\end{tabular}

* Significant intragroup changes over time $(\mathrm{p}<0.05)$.

\# Significant differences between groups at the referring time points of measurement $(\mathrm{p}<0.05)$.

n.d. not done; WBC = White Blood Cell Count; PLT = Platelet Count; IL6 = Interleukin-6 ; TNF- $\alpha=$ Tumor-Necrosis-Factor alpha $; \mathrm{Hb}=$ Hemoglobin

Table 2. Pulmonary Gas Exchange and Hemodynamics.

\begin{tabular}{|c|c|c|c|}
\hline & Baseline & $\begin{array}{l}\text { e Point of Measuren } \\
\text { 3h after Endotoxin }\end{array}$ & 6h after Endotoxin \\
\hline $\begin{array}{l}\mathrm{PaO}_{2},[\mathrm{mmHg}] \\
\text { Endotoxin* } \\
\text { Control }\end{array}$ & $\begin{array}{l}572.2 \pm 36.1 \\
603.1 \pm 42,2\end{array}$ & $\begin{array}{l}342.1 \pm 113.5 \# \\
610.4 \pm 48.6\end{array}$ & $\begin{array}{l}225.2 \pm 157.7 \# \\
628.2 \pm 41.2\end{array}$ \\
\hline $\begin{array}{l}\mathrm{PaCO}_{2}[\mathrm{mmHg}] \\
\text { Endotoxin* } \\
\text { Control }\end{array}$ & $\begin{array}{l}34.4 \pm 7.8 \\
30.5 \pm 5.6\end{array}$ & $\begin{array}{l}48.1 \pm 7.4 \# \\
28.0 \pm 5.1\end{array}$ & $\begin{array}{l}62.1 \pm 18.5 \# \\
28.7 \pm 5.8\end{array}$ \\
\hline $\begin{array}{l}\text { Minute ventilation }[\mathrm{ml} / \mathrm{kg} \cdot \mathrm{min}] \\
\text { Endotoxin } \\
\text { Control }\end{array}$ & $\begin{array}{l}223.1 \pm 43.8 \\
224.9 \pm 50.5\end{array}$ & $\begin{array}{l}244.9 \pm 30.8 \\
219.4 \pm 41.6\end{array}$ & $\begin{array}{l}234.9 \pm 57.9 \\
221.0 \pm 49.3\end{array}$ \\
\hline $\begin{array}{l}\text { Peak airway pressure }[\mathrm{mbar}] \\
\text { Endotoxin* } \\
\text { Control* }^{*}\end{array}$ & $\begin{array}{l}26.4 \pm 3.3 \\
29.4 \pm 2.4\end{array}$ & $\begin{array}{l}37.6 \pm 3.9 \\
32.0 \pm 2.8\end{array}$ & $\begin{array}{l}53.6 \pm 10.7 \# \\
36.9 \pm 5.2\end{array}$ \\
\hline $\begin{array}{l}\text { Norepinephrine requirements }[\mathrm{mg} / \mathrm{h}] \\
\text { Endotoxin } \\
\text { Control }\end{array}$ & $\begin{array}{c}0.15 \pm 0.09 \# \\
0.0\end{array}$ & $\begin{array}{c}0.05 \pm 0.04 \\
0.0\end{array}$ & $\begin{array}{c}0.15 \pm 0.12 \# \\
0.0\end{array}$ \\
\hline $\begin{array}{l}\text { MAP }[\mathrm{mmHg}] \\
\text { Endotoxin } \\
\text { Control }\end{array}$ & $\begin{array}{l}72.3 \pm 7.3 \\
90.1 \pm 12.2\end{array}$ & $\begin{array}{l}67.0 \pm 9.2 \\
82.1 \pm 9.6\end{array}$ & $\begin{array}{l}67.6 \pm 11.3 \\
72.5 \pm 8.4\end{array}$ \\
\hline $\begin{array}{l}\text { Heart Rate }\left[\mathrm{min}^{-1}\right] \\
\text { Endotoxin* } \\
\text { Control* }\end{array}$ & $\begin{array}{l}86 \pm 17 \\
90 \pm 12\end{array}$ & $\begin{array}{c}110 \pm 17 \\
82 \pm 9\end{array}$ & $\begin{array}{c}124 \pm 20 \# \\
78 \pm 13\end{array}$ \\
\hline $\begin{array}{l}\text { LVEDP }[\mathrm{mmHg}] \\
\text { Endotoxin } \\
\text { Control }\end{array}$ & $\begin{array}{l}9.0 \pm 1.2 \\
8.4 \pm 0.2\end{array}$ & $\begin{array}{l}9.1 \pm 1.3 \\
8.3 \pm 0.7\end{array}$ & $\begin{array}{l}9.0 \pm 2.1 \\
8.3 \pm 0.4\end{array}$ \\
\hline
\end{tabular}

* Significant changes over time within a group $(\mathrm{p}<0.05)$. \# Significant differences between groups at the referring time points of measurement $(\mathrm{p}<0.05)$.

$\mathrm{PaO}_{2}$ : Arterial oxygen tension; $\mathrm{PaCO}_{2}$ : Arterial carbondioxid tension; MAP: Mean arterial blood pressure; LVEDP: Left ventricular enddiastolic blood pressure 


\section{Heparan Sulfate:}

Serum HS concentrations did not change in the CG during the observation period, but significantly increased over time in the EG $(p<0.001$, T2). (Fig. 1).

\section{Markers of Inflammation:}

In accordance with respiratory and hemodynamic parameters baseline values displayed no differences between the groups (Table 1). In the control group we noticed a moderate, but significant increase in IL6 plasma concentration over time, whereas no relevant alterations of WBC, PLTS and TNF- $\alpha$ were observed. In contrast, in the endotoxin group all these inflammation markers significantly changed compared to baseline and compared to the control group (Table 1). Mean serum hemoglobin concentrations (Table 1) and hematocrit (not shown) did not differ significantly throughout the study.

\section{Pulmonary Gas Exchange and Hemodynamics:}

All respiratory and ventilatory parameters (except minute ventilation) significantly declined in the EG compared to the CG (Table 2). MAP and LVEDP were kept at a constant level in both study groups, but, with proceeding systemic inflammation, significantly increased fluid and catecholamine application rates were necessary to maintain stable hemodynamics in the EG (Table 2). During the observation period, cumulative fluid requirements to keep left ventricular end-diastolic pressure at $8 \mathrm{mmHg}$ were $1810 \mathrm{ml}$ (EG) versus $600 \mathrm{ml}(\mathrm{CG})(\mathrm{p}<0.05)$.

\section{DisCUSSION}

The EGX is a vulnerable structure that can be damaged by various pathomechanisms, which are of considerable clinical relevance, such as ischemia and reperfusion $[20,25]$. The loss of EGX components (HS, Syndecan-1) was observed after exposure to a variety of stimuli including the cytokines IL-1 $\beta$ and TNF- $\alpha$ [16], neutrophil-activation $[26,27]$ or human oxidized LDL [15, 28, 29].

Klein et al. $[26,27,30]$ demonstrated in an vitro model on cultured human umbilical vein endothelial cells that activated neutrophils pre-treated with Escherichia coli endotoxin caused a reduction of endothelial GAGs. In this investigation, an animal mod$\mathrm{el}$, which is easier to control than a clinical trial but nevertheless is stronger related to clinical medicine than in vitro studies, was applied. The study was designed to be a starting point for further investigations concerning the relationship between sepsis and EGXpathology. According to its design the investigation was solely descriptive.

The main findings of the current study were that the administration of bacterial endotoxins to healthy, anesthetized pigs led to a significant increase in serum HS concentrations and that animals in the EG required three times the amount of intravenous fluids compared to the CG to maintain stable hemodynamics.

Independent of the importance intracellular endothelial structures have for vascular integrity, it has been shown that the EGX serves as a first barrier to prevent fluid losses from the intravascular space to the interstitium [1, 30-32] and that even the Starling model of transendothelial fluid exchange might have to be redefined. In a study performed by van den Bergh et al. [32] only the intact EGX protected against myocardial edema and one can speculate that this observation might have general validity for the whole vascular bed. The results of the current study are indicating that the EGX gets damaged in the presence of bacterial endotoxins, thus leading to an enhanced vascular permeability. This should be of special interest in septicemia because a capillary leak syndrome with generalized edema is one of the most frequent symptoms of sepsis. Interestingly hemoglobin and hematocrit did not change significantly during the time course in the EG. Obviously a relevant hemodilution did not occur in this group despite the heavily increased amount of intravenous fluid substitution. Though the actual blood volume was not measured in the current investigation, one can speculate that fluids that were administered via an intravenous line instantly left the intravascular system because of a "capillary leak" caused by a defect EGX. On the other hand, HS concentrations were only weakly correlated with fluid requirements necessary to keep a constant LVEDP $(r=0.29)$. This weak coherency emphasizes the assumption that shedding of the EGX is only one of the multiple factors determining fluid loss and fluid requirements in sepsis.

Despite the fact that there are some pathophysiological differences between endotoxemia and clinical sepsis, in the current study, IL6 and TNF- $\alpha$ were significantly elevated in the EG. It is well known, that the local injection of pure inflammatory mediators induces venular leakage [33] and several investigators found that TNF- $\alpha$ causes a diminution of the EGX in in vitro models $[17,26]$. In our study we could not differentiate, whether the destruction of the EGX was directly caused by endotoxins or by TNF- $\alpha$, whose release was triggered by bacterial lipopolysaccharides. This question will be of interest in further studies, because TNF- $\alpha$ serum concentration might be a target of therapeutical approaches in the future. Concerning the integrity of the EGX Hydrocortisol as well as Antithrombin III have shown to be protective in an isolated ischemic heart model [16, 20]. Further research will show whether these substances are able to prevent shedding of the EGX in endotoxemia, too.

In two clinical studies on septic patients Oragui [34] and Nelson [35] observed increased plasma-and urine concentrations of GAGs (and Syndecan-1) and related these to changes in glomerular permeability as well as to overall mortality and the antibacterial actions of plasma.

However, these investigations had some restrictions: Especially in Oragui's investigation the diagnosis "sepsis" was exclusively based on clinical symptoms as described by the American College of Chest Physicians/Society of Critical Care Medicine Consensus Conference in 1992 [36], whereas Nelson also measured $\mathrm{C}$-reactive protein and procalcitonin to obtain an increased level of diagnostic security. In both trials the diagnosis "sepsis" and was not confirmed by blood cultures and - as a consequence - "endotoxemia" could not be attested without doubt. The results of the current investigation support the findings of 
Oragui and Nelson on a more experimental basis, explicitly demonstrating that bacterial endotoxins can damage the EGX to a so far undefined extend. Coexisting conditions, like previous illnesses, age, surgical therapy, drug therapy and others, whose influence on the EGX is entirely unknown and which can never be excluded completely in clinical trials could be reduced to two items: anesthesia and artificial ventilation. However, these factors were standardized in both study groups and should not have influenced the intergroup comparison.

In contrast to rising Serum HS-levels we noticed a considerable decrease of serum leukocyte- and platelet counts during the $6 \mathrm{~h}$ observation period; a phenomenon which regularly occurs in severe early sepsis. There is some information in the literature that there might be causal relationship between a degradation of the EGX and leukocyte-adhesion. For example Vink [15] and Constantinescu [29] observed that a degradation of the EGX stimulates leukocyte and platelet-endothelial cell adhesion. Furthermore, they observed that the systemic leukocyte counts moderately decreased after a systemic, additional bolus of oxidized LDL indicating that leukocyte immobilization occurred in multiple organs, which probably induced a depletion of the leukocyte rolling bloodstream. In accordance with the descriptive character of the study we regard the changes in leukocyte and platelet counts as an interesting phenomenon, worthwhile to report, but abstained from practising statistical tests or speculations on the physiological basis of this effect. This has to be determined in further studies.

\section{CONCLUSION}

In an animal model, the administration of bacterial endotoxins caused significantly elevated levels of IL6 and TNF- $\alpha$ and was accompanied by a relevant increase in serum-heparan sulfate concentrations as well as decreased leukocyte and platelet counts. Further studies will be necessary to investigate whether this result is reproducible in humans, and will be helpful in diagnostics and/or therapy of septic diseases.

The results of the study presented in the current work were worked out in the Clinic of Anesthesia, Ludwig-MaximiliansUniversity, City of Munich, Germany.

This work was supported by a grant from the Scientific Editorial Board of the Munich Medical Weekly, Munich, Bavaria, Germany. Drager-Werke (Lübeck, Germany) provided technical support.

\section{REFERENCES}

1. Rehm M, Zahler S, Lotsch M, et al. Endothelial glycocalyx as an additional barrier determining extravasation of $6 \%$ hydroxyethyl starch or $5 \%$ albumin solutions in the coronary vascular bed. Anesthesiology. 2004 May; 100(5): 1211-23.

2. Pries AR, Secomb TW, Gaehtgens P. The endothelial surface layer. Pflugers Arch. 2000 Sep; 440(5): 653-66.

3. Lindahl U, Hook M. Glycosaminoglycans and their binding to biological macromolecules. Annu Rev Biochem. 1978; 47: 385-417.
4. Jacob M, Bruegger D, Rehm M, et al. The endothelial glycocalyx affords compatibility of Starling's principle and high cardiac interstitial albumin levels. Cardiovasc Res. 2007 Feb 1; 73(3): 575-86

5. Adamson RH, Lenz JF, Zhang X, Adamson GN, Weinbaum S, Curry FE. Oncotic pressures opposing filtration across non-fenestrated rat microvessels. J Physiol. 2004 Jun 15; 557(Pt 3): 889-907.

6. Bruegger D, Jacob M, Rehm M, et al. Atrial natriuretic peptide induces shedding of endothelial glycocalyx in coronary vascular bed of guinea pig hearts. Am J Physiol Heart Circ Physiol. 2005 Nov; 289(5): H1993-H1999.

7. Platts SH, Linden J, Duling BR. Rapid modification of the glycocalyx caused by ischemia-reperfusion is inhibited by adenosine A2A receptor activation. Am J Physiol Heart Circ Physiol. 2003 Jun; 284(6): H2360-H2367.

8. Gouverneur M, Berg B, Nieuwdorp M, Stroes E, Vink H. Vasculoprotective properties of the endothelial glycocalyx: effects of fluid shear stress. J Intern Med. 2006 Apr; 259(4): 393-400.

9. Kuchan MJ, Frangos JA. Role of calcium and calmodulin in flow-induced nitric oxide production in endothelial cells. Am J Physiol. 1994 Mar; 266(3 Pt 1): C628-C636.

10. Chang YS, Yaccino JA, Lakshminarayanan S, Frangos JA, Tarbell JM. Shear-induced increase in hydraulic conductivity in endothelial cells is mediated by a nitric oxide-dependent mechanism. Arterioscler Thromb Vasc Biol. 2000 Jan; 20(1): 35-42.

11. Mochizuki S, Vink H, Hiramatsu O, et al. Role of hyaluronic acid glycosaminoglycans in shear-induced endothelium-derived nitric oxide release. Am J Physiol Heart Circ Physiol. 2003 Aug; 285(2): H722-H726.

12. Sabri S, Soler M, Foa C, Pierres A, Benoliel A, Bongrand P. Glycocalyx modulation is a physiological means of regulating cell adhesion. J Cell Sci. 2000 May; 113 ( Pt 9): 1589-600.

13. Soler M, splat-Jego S, Vacher B, et al. Adhesion-related glycocalyx study: quantitative approach with imagingspectrum in the energy filtering transmission electron microscope (EFTEM). FEBS Lett. 1998 Jun 5; 429(1): 8994.

14. Constantinescu AA, Vink H, Spaan JA. Elevated capillary tube hematocrit reflects degradation of endothelial cell glycocalyx by oxidized LDL. Am J Physiol Heart Circ Physiol. 2001 Mar; 280(3): H1051-H1057.

15. Vink H, Constantinescu AA, Spaan JA. Oxidized lipoproteins degrade the endothelial surface layer : implications for platelet-endothelial cell adhesion. Circulation. 2000 Apr 4; 101(13): 1500-2.

16. Chappell D, Hofmann-Kiefer K, Jacob M, et al. TNF-alpha induced shedding of the endothelial glycocalyx is prevented by hydrocortisone and antithrombin. Basic Res Cardiol. 2009 Jan; 104(1): 78-89.

17. Henry CB, Duling BR. TNF-alpha increases entry of macromolecules into luminal endothelial cell glycocalyx. Am J Physiol Heart Circ Physiol. 2000 Dec; 279(6): H2815-H2823.

18. Kurzelewski M, Czarnowska E, Beresewicz A. Superoxide- and nitric oxide-derived species mediate endothelial dysfunction, endothelial glycocalyx disruption, and enhanced neutrophil adhesion in the post-ischemic guineapig heart. J Physiol Pharmacol. 2005 Jun; 56(2): 163-78.

19. Rubio-Gayosso I, Platts SH, Duling BR. Reactive oxygen species mediate modification of glycocalyx during ischemia-reperfusion injury. Am J Physiol Heart Circ Physiol. 2006 Jun; 290(6): H2247-H2256.

20. Chappell D, Jacob M, Hofmann-Kiefer K, et al. Hydrocortisone Preserves the Vascular Barrier by Protecting the Endothelial Glycocalyx. Anesthesiology. 2007 Nov 1; 108(5): 776-84. 
21. Jacob M, Chappell D, Hofmann-Kiefer K, Conzen P, Peter K, Rehm M. [Determinants of insensible fluid loss : Perspiration, protein shift and endothelial glycocalyx.]. Anaesthesist. 2007 Aug; 56(8): 747-64.

22. Bauer P.R. Microvascular responses to sepsis: clinical significance. Pathophysiology. 2002 Jun 1; 8(3): 141-8.

23. Lush C.W., Kvietys P.R. Microvascular dysfunction in sepsis. Microcirculation. 2000 Apr 1; 7(2): 83-101.

24. Vincent J.L. Microvascular endothelial dysfunction: a renewed appreciation of sepsis pathophysiology. Crit Care. 2001 May 1; 5(Suppl 2): 1-5.

25. Rehm M, Bruegger D, Christ F, et al. Shedding of the Endothelial Glycocalyx in Patients Undergoing Major Vascular Surgery With Global and Regional Ischemia. Circulation. 2007 Oct 8; 116(17): 1896-906.

26. Heyderman RS, Klein NJ, Shennan GI, Levin M. Reduction of the anticoagulant activity of glycosaminoglycans on the surface of the vascular endothelium by endotoxin and neutrophils: evaluation by an amidolytic assay. Thromb Res. 1992 Sep 15; 67(6): 677-85.

27. Klein NJ, Levin M, Strobel S, Finn A. Degradation of glycosaminoglycans and fibronectin on endotoxin-stimulated endothelium by adherent neutrophils: relationship to CD11b/CD18 and L-selectin expression. J Infect Dis. 1993 Apr; 167(4): 890-8.

28. Van Teeffelen JW, Brands J, Stroes ES, Vink H. Endothelial glycocalyx: sweet shield of blood vessels. Trends Cardiovasc Med. 2007 Apr; 17(3): 101-5.

29. Constantinescu AA, Vink H, Spaan JA. Endothelial cell glycocalyx modulates immobilization of leukocytes at the endothelial surface. Arterioscler Thromb Vasc Biol. 2003 Sep 1; 23(9): 1541-7.

30. Klein NJ, Shennan GI, Heyderman RS, Levin M. Alteration in glycosaminoglycan metabolism and surface charge on human umbilical vein endothelial cells induced by cytokines, endotoxin and neutrophils. J Cell Sci. 1992 Aug; 102 ( Pt 4): 821-32.

31. Jacob M, Rehm M, Loetsch M, et al. The Endothelial Glycocalyx Prefers Albumin for Evoking Shear Stress-Induced, Nitric Oxide-Mediated Coronary Dilatation. J Vasc Res. 2007 Jul 2; 44(6): 435-43.
32. van den Berg BM, Vink H, Spaan JA. The endothelial glycocalyx protects against myocardial edema. Circ Res. 2003 Apr 4; 92(6): 592-4.

33. Joris I, Cuenoud HF, Doern GV, Underwood JM, Majno G. Capillary leakage in inflammation. A study by vascular labeling. Am J Pathol. 1990 Dec; 137(6): 1353-63.

34. Oragui EE, Nadel S, Kyd P, Levin M. Increased excretion of urinary glycosaminoglycans in meningococcal septicemia and their relationship to proteinuria. Crit Care Med. 2000 Oct 1; 28(8): 3002-8.

35. Nelson A, Berkestedt I, Schmidtchen A, Ljunggren L, Bodelsson M. Increased levels of glycosaminoglycans during septic shock: relation to mortality and the antibacterial actions of plasma. Shock. 2008 Dec; 30(6): 623-7.

36. American College of Chest Physicians/Society of Critical Care Medicine Consensus Conference: definitions for sepsis and organ failure and guidelines for the use of innovative therapies in sepsis. Crit Care Med. 1992 Jun; 20(6): 864-74

Received: June 23, 2009 / Accepted: July 27, 2009

Address for correspondence:

Dr. Klaus F. Hofmann-Kiefer

Klinik für Anaesthesiologie

Ludwig-Maximilians-Universität München

Klinikum Innenstadt

Maistr.11,

80337 München

Germany

Tel.: $\quad+49895160-4500$

Fax: + $49895160-4909$

E-mail: Klaus.Hofmann-Kiefer@med.uni-muenchen.de 